\title{
A case control study on the effect of threatened miscarriage on selected pregnancy outcomes
}

\author{
Bimsara H Perera ${ }^{1}$, A Pubudu De Silva ${ }^{2}$, Hemantha Perera ${ }^{3}$ \\ Sri Lanka Journal of Obstetrics and Gynaecology 2009; 31: 34-38
}

\begin{abstract}
Objective: To describe and ascertain adverse pregnancy outcomes in mothers with threatened miscarriage.
\end{abstract}

Methods: A case control study involving 110 mothers with threatened miscarriage during the first 14 weeks of pregnancy with 220 age and parity matched controls The study period was one year from November 2006 and conducted at Sri Jayewardenepura General Hospital (SJGH), Nugegoda.

Results: The mean maternal age of the study group was 28.8 (SD - 4.6) years and 69 (62.7\%) of the mothers were nulli parous while 34 $(30.9 \%)$ were multi parous women. The complications seen in the study group were preterm delivery $12(10.9 \%)$, preterm premature rupture of membranes $7(6.4 \%)$, placental abruption $6(5.5 \%)$, small for gestation 20 $(18.2 \%)$ and manual removal of placenta 2 $(1.8 \%)$. When compared with age and parity matched controls there was a significant increase in pregnancy induced hypertension and its complications (Pearson's $\chi 2=8.224$, $\mathrm{P}<0.05$ ) and fetal growth restriction (Pearson's $\chi 2=5.029, \mathrm{P}<0.025)$. There was no statistically significant difference between the two groups with regard to pre term pre labour rupture of membranes, caesarean section, delivery of babies small for gestational age and manual removal of the placenta.

\footnotetext{
${ }^{1}$ Registrar in Obstetrics and Gynaecology, Sri Jayewardenepura General Hospital, Nugegoda.

${ }^{2}$ Registrar in Community Medicine, Department of Community Medicine, Faculty of Medicine, University of Colombo.

${ }^{3}$ Consultant Obstetrician and Gynaecologist, Sri Jayewardenepura General Hospital, Nugegoda.

Correspondence: Bimsara H Perera

E-mail:bhplk@yahoo.com
}

Conclusion: Threatened miscarriage is associated with placental abruption, pregnancy induced hypertension and fetal growth restriction.

Key words: Threatened miscarriage.

\section{Introduction}

Threatened miscarriage is one of the most common complications of pregnancy which affects $16-25 \%$ of all pregnancies ${ }^{1,2}$. The presumptive diagnosis of a threatened miscarriage is based on a history of vaginal bleeding in early pregnancy in the presence of a closed cervix. The diagnosis is confirmed by ultrasonic evidence of an intrauterine gestational sac with a positive fetal heart ${ }^{3}$. When pregnant patients have bleeding, it may cause stress and anxiety for the mother to be about the future outcome of the pregnancy. The outcome of ongoing pregnancies after first-trimester bleeding is of relevance to obstetricians for planning antenatal care and clinical interventions in pregnancy.

In general, the incidence of spontaneous abortion after first trimester bleeding is quoted to be $50 \%$ before sonographic evaluation for fetal viability ${ }^{1,4}$. If a viable fetus is noted at ultrasound examination after first trimester vaginal bleeding, $95-98 \%$ of such pregnancies will still continue beyond 20 weeks of gestation ${ }^{1,5}$. Although few studies have evaluated outcomes other than viability at term, most agree that adverse pregnancy outcome is associated with first trimester vaginal bleeding ${ }^{1,6}$. Complete miscarriage is 2.6 times as likely ${ }^{7}$ and $17 \%$ of cases are expected to develop complications later in pregnancy ${ }^{8}$.

Even though threatened miscarriage is associated with various adverse pregnancy outcomes, they are ill defined. At the moment mothers with threatened miscarriage are considered 'high risk' only during the period when they are having per vaginal bleeding.

\section{Objective}

The aim of this research was to find out whether adverse pregnancy outcomes are commonly associated in mothers with threatened miscarriage in Sri Lanka. 


\section{Materials and methods}

This was a case control study done in antenatal clinic and ward 9 SJGH from November 2006 to October 2007. The study included a cohort of pregnant mothers with a history of threatened miscarriage during the first fourteen weeks of pregnancy, who were registered, followed up at antenatal clinics and delivered at Ward 09 SJGH along with aged and parity matched controls.

The adverse pregnancy outcome following threatened miscarriage after analyzing the previous studies ${ }^{9}$ were $13.8 \%$ compared to $6.0 \%$ in the control group respectively. The number of mothers taken as cases was 110 and controls were 220. All the mothers who presented with threatened miscarriage during the study period were selected till the stipulated sample size was achieved.

Mothers with multiple pregnancies were excluded, as were women with congenital uterine abnormalities, having large leiomyomata distorting the uterus and also women with known thrombophilia. Only women with frank per vaginal bleeding included even women with mild bleeding or spotting excluded.
The following outcome measures were selected: i. Preterm delivery, ii. Preterm pre labour rupture of membranes, iii. Pre eclampsia, iv. Placental abruption, v. Placenta Praevia, vi. Fetal Growth Restriction, vii. Caesarean section, iii. Delivery of babies Small for Gestational Age (SGA) and ix. Manual removal of placenta. Fetal growth restriction was assessed by observing the growth charts where fetal biometry was plotted.

All data were coded and was entered using EXCEL 2007 and analysed using the SPSS 16 computer package. Measures of central tendency were used to describe the continuous data.

Tests of significance were used to compare groups ${ }^{10}$. The $\chi^{2}$ test was applied to compare differences between categorical variables. A probability of 0.05 was considered statistically significant.

\section{Results}

The study included 110 mothers with a history of threatened miscarriage during the first trimester and 220 controls. Demographic data and overall outcomes of two groups are presented in Table 1 .

Table 1. Characteristics and outcomes in $\mathbf{1 1 0}$ women with threatened miscarriage compared with 220 controls

\begin{tabular}{lcc}
\hline Characteristics & Study Group & Control Group \\
\hline Mean maternal Age & $28.8(+/-9.2)$ & $27.3(\mathrm{SD}+/-8.6)$ \\
Maternal Age Range & $19-42$ & $19-42$ \\
Mean BMI* at booking & $22.5(+/-2.8)$ & $21.25(+/-4.12)$ \\
Maternal BMI Range & $17.2-30.85$ & $13.7-32.43$ \\
POA $^{* *}$ at Booking & 8.7 & 9.6 \\
POA at Delivery & $38.43(+/-2.01)$ & $39.24(+/-1.27)$ \\
\hline
\end{tabular}

*BMI $=$ Body Mass Index,${ }^{* *}$ POA $=$ Period of Amenorrhoea

The mean maternal ages in both the study and the control groups were 28.8 and 27.3 years respectively. About 96\% (96 mothers) of the mothers whose pregnancy continued and assessed had their initial bleeding after 8 weeks of gestation. Most of the (69 or 62\%) mothers who presented with bleeding were in their first pregnancies. 
The obstetric and perinatal outcomes for women with and those without threatened miscarriage are shown in Table 02. There was a statistically significant increase in preterm delivery rate in mothers with threatened miscarriage.

However when it was subdivided according to the period of gestation 34 weeks and less did not show a statistically significant difference.

Table 2. Obstetric and perinatal outcome in women with first-trimester bleeding

\begin{tabular}{|c|c|c|c|c|c|}
\hline Pregnancy outcome & $\begin{array}{c}\text { Threatened } \\
\text { Miscarriage } \\
(n=110)\end{array}$ & $\%$ & $\begin{array}{l}\text { Control } \\
(n=220)\end{array}$ & $\%$ & Probability \\
\hline Preterm Delivery & 12 & 10.9 & 5 & 2.3 & 0.003 \\
\hline Delivery at 34 to $36+6$ & 7 & 6.4 & 2 & 0.9 & - \\
\hline Delivery at 28 to $33+6$ & 5 & 4.5 & 3 & 1.4 & - \\
\hline *PPROM & 12 & 10.9 & 23 & 10.5 & 0.899 \\
\hline Preeclampsia & 7 & 6.4 & 2 & 0.9 & 0.003 \\
\hline Placental Abruption & 6 & 5.5 & 0 & 0 & - \\
\hline Placenta Praevia & 0 & 0 & 5 & 2.3 & - \\
\hline Fetal Growth Restriction & 9 & 8.2 & 6 & 2.7 & 0.025 \\
\hline $\begin{array}{l}\text { Delivery of **SGA babies }(<10 \text { th centile) } \\
* * * \text { LSCS }\end{array}$ & $\begin{array}{l}20 \\
33\end{array}$ & $\begin{array}{c}18.2 \\
30\end{array}$ & $\begin{array}{l}52 \\
47\end{array}$ & $\begin{array}{l}23.6 \\
21.4\end{array}$ & $\begin{array}{l}0.258 \\
0.084\end{array}$ \\
\hline Instrumental delivery & 4 & 3.63 & 7 & 3.18 & 0.828 \\
\hline Manual removal of placenta & 2 & 1.8 & 0 & 0 & - \\
\hline$* * * *$ NICU admission & 21 & 19.1 & 23 & 10.5 & 0.3 \\
\hline
\end{tabular}

*PPROM = Pre term Premature Rupture of Membranes; **SGA = Small for Gestational Age;

${ }^{* * *}$ LSCS $=$ Lower Segment Caesarean Section; ${ }^{* * * * N I C U ~}=$ Neonatal Intensive Care Unit.

The premature rupture of membranes among study group and control showed similar percentages and statistically not significant. There was a statistically significant increase in occurrence of preeclampsia among mothers with threatened miscarriage.

Occurrence of placental abruption was seen in mothers with threatened miscarriage and not seen in the control group. The fetal growth restriction rate among the study group was $8.2 \%$ as opposed to $2.7 \%$ which was a statistically significant increase.

The mean birth weight is dependent on gestation, ethnicity, maternal weight, height, and sex of the baby. The weight centiles for both cases and controls were calculated using the above variables, using a centile calculator available online from the Perinatal Institute for Maternal and Child Health, and no differences were found between the two groups $(p=0.258)$.

There was also no statistically significant difference in either in caesarean section rate or in the instrumental delivery rate. The manual removal of the placentae was only done in the study population. There was no difference in rate of admission to the neonatal intensive care unit in both groups.

\section{Discussion}

This study demonstrated a clear association between preterm delivery, pregnancy induced hypertension, placental abruption and fetal growth restriction in mothers with threatened miscarriage in the first trimester. 
The occurrence of preterm delivery in mothers with threatened miscarriage had been a consistent finding in most of the previous studies ${ }^{1,9,11,12,13,14,15,16}$.

The increased occurrence of pre-eclampsia among mothers with first trimester vaginal bleeding had been demonstrated by previous study done by Verma et al in $199^{36}$. The study done by Weiss et al also had demonstrated that pre-eclampsia was common among mothers with threatened miscarriage but then it had been restricted to the mothers with mild bleeding or spotting 9 .

Results of the current study along with the results of previous studies support the school of thinking that the first-trimester vaginal bleeding may indicate underlying placental dysfunction. The placental dysfunction may manifest in later pregnancy by a variety of adverse outcomes including preterm delivery, pregnancy induced hypertension, placental abruption and fetal growth restriction. Since preterm delivery was associated with threatened miscarriage, identifying women who are at "high risk" for preterm labour is important. Unfortunately the screening strategies are imprecise. These include screening for bacterial vaginosis and bio-physical markers, such as cervical length and fetal fibronectin. Many of these strategies depend heavily on a past history of preterm birth $^{17}$ or concentrate on correct diagnosis of women who already present with symptoms of preterm labour ${ }^{17}$ and therefore do not identify all women at risk. Development of inter-ventions, such as progesterone ${ }^{35}$ and antioxidant supplementation, clearly requires further investi-gation; however, identification of women at risk would allow such interventions to be implemented from a much earlier gestation. Increased antenatal surveillance, possibly with cervical length measure-ments or the use of fetal fibronectin tests, might identify women within this group who are at increased risk. This would result in a higher index of suspicion in women presenting with symptoms later in pregnancy, enabling prompt identification of these complications should they occur. Knowledge of this increased risk may also facilitate decision making regarding management, for example, timely administration of corticosteroids or decisions regarding mode, place, and timing of delivery, which will inevitably improve neonatal outcome.

One of the weaknesses of our study is that the exposure reporting was retrospective nature. The women were asked about bleeding during the first trimester at the time of the delivery. When women are experiencing bleeding they are very anxious that it might end up as a miscarriage. Thus it is a very significant event in their lives. Therefore the occurrence of recall bias is very low. One advantage of doing the study at Sri Jayawardenapura general hospital had been good record keeping. Each patient is given an individual medical record and on each visit entries are made into the same record. Thus it was easier for the principal investigator to verify the amount of bleeding by going through these medical records. Furthermore in order to reduce the errors that could occur due to recall bias the mothers were not grouped into mild and moderate categories and were not compared. Even then the ideal method would have been to conduct a prospective study in which mothers present with bleeding are assessed for the amount of bleeding and followed up till delivery. Furthermore in a prospective study the controls would be selected at the beginning of the study thus the selection bias would be minimal.

\section{Conclusion}

Threatened miscarriage is associated with placental abruption, pregnancy induced hypertension and fetal growth restriction.

\section{References}

1. Farrell T, Owen P. The significance of extra chorionic membrane separation in threatened miscarriage. Br J Obstet Gynaecol 1996; 103: 926-8.

2. Bowe P. Murphy H. Complications of pregnancy following Threatened Abortion Irish J Med Sci 1987; 156: 328-9.

3. Cunningham FG, Gant NF, Leveno KJ, Gilstrap LC, Hauth JC, Wenstrom KD, editors. William's obstetrics. 21st ed. New York (NY): McGraw-Hill; 2001.

4. Chung TKH, Sahota DS, Lau TK, Mongelli JMj, Spencer JAD, Haines CJ. Threatened abortion: prediction on viability based on signs and symptoms. Aus NZ J Obstet Gynaecol 1999; 39: 443-7.

5. Uerpairojkit B, Tannirandorn $Y$, Manotaya S, Somprasit C, Charoenvidhya D, Wacharaprechanont T, et al. Sonographic findings in clinically diagnosed threatened abortion. J Med Assoc Thai 2001; 84: 661-5.

6. Verma SK, Premi HK, Gupta TV, Thakur S, Gupta KB, Randhawa I. Perinatal outcome of pregnancies complicated by threatened abortion. J Indian Med Assoc. 1994; 92: 364-5.

7. Makrydimas G,Sebire NJ, Lolis D, Vlassis N, Nicoloides $\mathrm{KH}$. Fetal loss following ultrasound diagnosis of live fetus at 6-10 weeks of gestation. Ultasound Obstet Gynecol 2003; 22: $368-72$.

8. Johns J, Hyett J, Jauniaux E. Obstetric outcome after threatened miscarriage with and without a hematoma on ultrasound. Obstet Gynecol 2003; 102: 483-7.

9. Weiss JL, Malone FD, Vidaver J, Ball RH, Nyberg DA, Comstock $\mathrm{CH}$, et al. Threatened abortion: a risk factor for 
poor pregnancy outcome, a population-based screening study. Am J Obstet Gynecol 2004; 190: 745-50.

10. Spinthall RC. Basic Statistical Analysis, 6th ed. Allyn and Bacon: 2000.

11. Wijesiriwardana A,Bhattacharaya S, Shetty A, Smith N, et al. Obstetric outcome in women with Threatened miscarriage in the First Trimester. Obstet Gynecol 2006; 107(3): 557-62.

12. Johns J, Jauniaux E. Threatened miscarriage as a predictor of obstetric outcome. Obstet Gynecol 2006; 107(4): 483-7.

13. Batzofin JH, Fielding WL, Friedman EA. Effect of vaginal bleeding in early pregnancy on outcome. Obstet Gynecol 1984; 63: 515-8.

14. Williams MA, Mittendorf R, Lieberman E, Monson RR.
Adverse infant outcomes associated with first-trimester vaginal bleeding. Obstet Gynecol 1991; 78: 14-8.

15. Sipila P. Hartianinen-Sorri AL. Perinatal outcome of pregnancies complicated by vaginal bleeding. BJOG 1992; 99: 959-63.

16. Strobino B, Pantel-Silverman J. Gestational vaginal bleeding and pregnancy outcome. Am J Epidemiol 1989; 129: 806-15.

17. Iams JD. Prediction and early detection of preterm labor. Obstet Gynecol 2003; 101: 402-12.

18. da Fonseca EB, Bittar RE, Carvalho MH, Zugaib M. Prophylactic administration of progesterone by vaginal suppository to reduce the incidence of spontaneous preterm birth in women at increased risk: a randomized placebocontrolled doubleblind study. Am J Obstet Gynecol 2003; 188: 419-24. 